\title{
ACOUSTICS2008/3053 \\ Development of a social survey questionnaire of reactions to vibration in residential buildings
}

\author{
H. Howarth and M. J Griffin \\ Institute of Sound and Vibration Research, University of Southampton, Human Factors Research Unit, \\ SO17 1BJ Southampton, UK
}

\begin{abstract}
A social survey questionnaire has been developed to determine human responses to vibration in residential environments. The overall aim was to produce a robust methodology for obtaining responses that could be combined with vibration measurements so as to investigate dose-response relationships for vibration in residential buildings. The vibration considered included that from sources outside the control of residents (e.g., road, rail, industrial, construction). This paper describes the development of the questionnaire and explains its structure and content. A review of social surveys and field and laboratory studies of vibration and noise is included. Methods of analysing responses obtained to the questionnaire are summarised.
\end{abstract}

Keywords: questionnaire building vibration

Technical area: Noise (NS) - Euronoise

PACS \#1: 43.50.Qp Effects of noise on man and society (see also 43.66.Ed, and 43.80.Nd)

PACS \#2:

PACS \#3: 